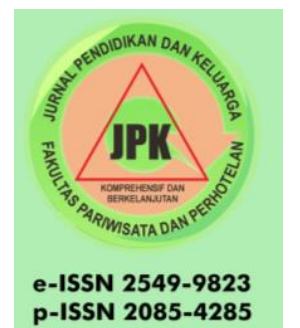

JURNAL PENDIDIKAN DAN KELUARGA

Vol. 11 No. 02, 2019 Page 284-291

DOI: https://doi.org/10.24036/jpk/vol11-iss02

available at http://jpk.ppj.unp.ac.id/index.php/jpk/index

\title{
PENILAIAN TAMPILAN VISUAL FEEDS DAN POSTINGAN INSTAGRAM HOTEL-HOTEL BERBINTANG DI KOTA PADANG SEBAGAI MEDIA PROMOSI ONLINE
}

\author{
Siti Atina Fajrianisa ${ }^{1}$, Yuliana $^{2}$ \\ ${ }^{1,2}$ Program Studi ManajemenPerhotelan \\ Jurusan Pariwisata \\ Fakultas Pariwisata dan Perhotelan \\ Universitas Negeri Padang \\ Email : siticavva@gmail.com \\ Published: 2019-12-31 \\ DOI: https://doi.org/10.24036/jpk/vol11-iss02/654 \\ URL:http://jpk.ppj.unp.ac.id/index.php/jpk/article/view/654
}

Submitted: 2019-08-12

Accepted: 2019-11-25

\begin{abstract}
The study began with the researchers observations on the visual display of feeds and Instagram posts of star hotels in the city of Padang. While people in the millenial era tend to use Instagram as a source of information when booking hotels. Then, there were many complaints about the online promotion media of these hotels for not providing the information as expected when in fact the hotel facilities were good and decent. The research aims to see the visual display of feeds and Instagram posts of star hotels in the city of Padang. This type of reseach is a descriptive study with a survey method. The research data was obtained by distributing asessment questionnaires compiled using a likert scale to assessors which included visual communication design experts, marketing experts and consumers. Data were analyzed using average scores based on assessor classification. From the research it was concluded that the visual display of feeds and Instagram posts of the star hotels in the city of Padang were in the category of not too good, not good, enough and good. And there is no one star hotels that is categorized as very good.

Key word: Visual display, feeds, posts, Instagram, hotel
\end{abstract}

\begin{abstract}
Abstrak
Penelitian berawal dari pengamatan peneliti terhadap tampilan visual feeds dan postingan Instagram hotel-hotel berbintang di kota Padang. Sementara masyarakat pada era milenial ini cenderung memanfaatkan Instagram sebagai sumber informasi ketika akan memesan hotel. Kemudian, banyaknya keluhan terhadap media promosi online hotel-hotel tersebut karena tidak memberi informasi sesuai yang diharapkan padahal sebenarnya fasilitas hotel tersebut bagus dan layak. Penelitian bertujuan untuk melihat tampilan visual feeds dan postingan Instagram hotel-hotel berbintang di kota Padang. Jenis penelitian adalah penelitian deskriptif dengan metode survei. Data penelitian didapat dengan menyebarkan angket penilaian yang disusun menggunakan skala likert kepada penilai yang meliputi ahli desain komunikasi visual, ahli pemasaran dan konsumen. Data dianalisis dengan menggunakan skor rata-rata berdasarkan klasifikasi penilai. Dari penelitian disimpulkan bahwa tampilan visual feeds dan postingan Instagram hotel-hotel berbintang di kota Padang tersebut berada pada kategori tidak baik, kurang baik, cukup dan baik. Dan tidak ada satu hotel berbintang pun yang berkategori sangat baik.

Kata Kunci: tampilan visual, feeds, postingan, Instagram, hotel
\end{abstract}

This is an open access article distributed under the Creative Commons 4.0 Attribution License, which permits unrestricted use, distribution, and reproduction in any medium, provided the original work is properly cited. ( 2017 by author and Universitas Negeri Padang. 


\section{Pendahuluan}

Pada saat sekarang ini, banyak hotel yang memanfaatkan Instagram sebagai media promosi. Hotel tersebut memasukkan foto-foto yang ditata secara grafis sehingga nilai jual produk menjadi lebih tinggi dan meninggalkan kesan estetis bagi konsumen. Hotel, khususnya bagian pemasaran, harus mampu menciptakan tampilan visual feeds dan postingan Instagram yang berkualitas. Filter serupa, tone warna senada, tata cara pengeditan, ukuran foto yang sama serta perhatian kepada kualitas foto yang diunggah adalah unsur dalam pembuatan tampilan visual feeds Instagram (Rizqia, 2017), yang nantinya akan dapat dinilai menggunakan prinsip desain visual meliputi keseimbangan, irama, proporsi, kesatuan dan dominasi (Ayu, 2013). Kemudian, perhatian kepada konsep, pencahayaan, objek, titik focus, warna, proporsi dan angle (Nurmarliana, 2017) adalah unsur dalam menghasilkan tampilan visual postingan Instagram, yang mana akan dapat dinilai menggunakan elemen desain meliputi garis, bentuk, kontras nilai, warna, tekstur, ilustrasi dan tipografi (Latifah, 2009).

Namun, tampilan visual feeds dan postingan Instagram hotel-hotel berbintang di kota Padang belum dibuat dengan dengan mempertimbangkan prinsip desain visual dan elemen desain sehingga tampilan visual tersebut menjadi kurang menarik dan belum berfungsi sebagai media promosi. Tidak menariknya tampilan visual feeds Instagram terlihat dari tidak adanya pemakaian dan penerapan filter serta tone warna yang serupa dan senada, ukuran foto yang diunggah juga tidak sama, kualitas foto yang diunggah tidak menggunakan teknik high definition sehingga foto terlihat buram. Kemudian, tidak menariknya tampilan visual postingan Instagram juga terlihat dari pengambilan foto yang yang kurang memperhatikan pose objek, angle, pencahayaan, titik fokus dan proporsi objek, serta editan postingan tidak proporsional seperti tipografi yang terlalu banyak sehingga menimbulkan kesan ramai dan mempengaruhi feeds. Padahal, jika feeds dan postingan Instagram hotel-hotel tersebut dibuat berdasarkan prinsip desain visual dan elemen desain, maka akan terlihat harmonis dan proporsional sehingga dapat mengirimkan sinyal estetis kepada pengunjung Instagram yang akan membuat sinyal estetis kepada pengunjung yang akan membuat mereka tertarik untuk melihat produk dan fasilitas hotel dengan lebih detail. Hal ini tentu akan berdampak positif terhadap hotel karena calon konsumen akan lebih memperhatikan produk yang ditawarkan. Kesan estetis juga akan dapat tersimpan di otak konsumen (Surajiyo, 2009) sehingga jika pada suatu saat nanti konsumen membutuhkan informasi tentang hotel dan produknya, mereka akan kembali membuka kembali instagram hotel tersebut.

Oleh karena itu, media promosi ini harus dirancang sedemikian rupa agar tujuan tersebut dapat tercapai. Hal inilah yang membuat pentingnya ahli pemasaran bekerja sama dengan ahli desain komunikasi visual dalam merancang media promosi online. Karena tampilan visual yang terencana dengan baik dapat mempermudah dan mempercepat informasi, membantu menghasilkan makna cerita, menyentuh emosi sehingga membuat informasi lebih berkesan dan membantu menghubungkan produk dengan permerekan (branding).

\section{Metode}

Jenis penelitian ini adalah penelitian deskriptif dengan metode survei. Penelitian dilaksanakan pada bulan Mei-Juni 2019 dengan objek penelitian sebagai berikut: 
Table 1 Objek Penelitian

\begin{tabular}{|c|c|c|c|c|}
\hline No & Klasifikasi Hote & No & Nama Hotel & Akun Instagram \\
\hline \multirow[t]{2}{*}{1} & \multirow[t]{2}{*}{$*$} & 1 & Hotel Hangtuah & @hotelhangtuah \\
\hline & & 2 & The Sriwijaya Hotel & @ thesriwijayahotel \\
\hline \multirow[t]{2}{*}{2} & \multirow[t]{2}{*}{$* *$} & 3 & Amaris Hotel & @amarispadang \\
\hline & & 4 & Plan B Hotel & @planbhotel \\
\hline \multirow[t]{3}{*}{3} & \multirow[t]{3}{*}{$* * *$} & 5 & Daima Hotel & @ daimahotel_padang \\
\hline & & 6 & Fave Hotel Olo & @ favehotelolopadang \\
\hline & & 7 & Ibis Hotel & @ibispadanghotel \\
\hline \multirow[t]{3}{*}{4} & \multirow[t]{3}{*}{$* * * *$} & 8 & Grand Inna Hotel & @ grandinnapadang \\
\hline & & 9 & Grand Zuri Hotel & @grandzuripadang \\
\hline & & 10 & Kyriad Hotel Bumiminang & @kyriadbumiminang \\
\hline
\end{tabular}

Sumber: data penelitian, 2019

Data sekunder yang digunakan dalam penelitian ini adalah tangkapan layar feeds dan postingan Instagram hotel-hotel non bintang diatas. Penangkapan layar postingan Instagram didasarkan kepada survei liked terbanyak oleh situs bestnine.com, dengan total tangkapan layar adalah sebagai berikut:

Table 2 Data Sekunder Penelitian

\begin{tabular}{llll}
\hline \multirow{2}{*}{ No } & \multirow{2}{*}{ Hotel } & \multicolumn{2}{l}{ Jumlah Tangkapan Layar } \\
\cline { 3 - 4 } & & Feeds & Postingan \\
\hline 1 & Hotel Hangtuah & 1 & 1 \\
\hline 2 & The Sriwijaya Hotel & 1 & 1 \\
\hline 3 & Amaris Hotel & 1 & 1 \\
\hline 4 & Plan B Hotel & 1 & 1 \\
\hline 5 & Daima Hotel & 1 & 1 \\
\hline 6 & Fave Hotel Olo & 1 & 1 \\
\hline 7 & Ibis Hotel & 1 & 1 \\
\hline 8 & Grand Inna Hotel & 1 & 1 \\
\hline 9 & Grand Zuri Hotel & 1 & 1 \\
\hline 10 & Kyriad Hotel Bumiminang & 1 & 1 \\
\hline & & 10 & 10 \\
\hline
\end{tabular}

Sumber: data penelitian, 2019

Teknik pengumpulan data menggunakan angket penilaian yang disusun dengan rentang skala likert sebagai berikut:

Table 3 Rentang Skala Likert

\begin{tabular}{ll}
\hline Pilihan Jawaban & Rentang Skala Likert \\
\hline Sangat Baik & $81-100$ \\
\hline Baik & $61-80$ \\
\hline Cukup & $41-60$ \\
\hline Kurang Baik & $21-40$ \\
\hline Tidak Baik & $0-20$
\end{tabular}

Sumber: Sugiyono, 2015 
Angket penilaian disebarkan kepada sembilan penilai dengan masing-masing kategori sebagai berikut:

Table 4 Penilai

\begin{tabular}{ll}
\hline Kategori Penilai & Jumlah \\
\hline Ahli Desain Komunikasi Visual & 3 \\
\hline Ahli Pemasaran & 3 \\
\hline Konsumen & 3 \\
\hline
\end{tabular}

Sumber: data penelitian, 2019

Data dianalisis dengan mencari nilai skor rata-rata berdasarkan rentang skala likert pada setiap tampilan visual feeds dan postingan Instagram hotel-hotel berbintang di kota Padang.

\section{Hasil Dan Pembahasan}

Dari hasil penilaian, didapatkan nilai rata-rata tampilan visual feeds Instagram hotelhotel berbintang di kota Padang adalah sebagai berikut:

Table 5 Nilai Rata-rata Tampilan Visual Feeds Instagram Hotel-hotel Berbintang di Kota Padang

\begin{tabular}{|l|l|l|l|l|l|}
\hline No & Hotel & $\begin{array}{l}\text { Ahli } \\
\text { DKV }\end{array}$ & $\begin{array}{l}\text { Ahli } \\
\text { Pemasaran }\end{array}$ & Konsumen & $\begin{array}{l}\text { Total } \\
\text { Rata-rata }\end{array}$ \\
\hline 1 & Hotel Hangtuah & 43 & 63 & 40 & 49 \\
\hline 2 & The Sriwijaya Hotel & 53 & 53 & 75 & 60 \\
\hline 3 & Amaris Hotel & 50 & 55 & 74 & 60 \\
\hline 4 & Plan B Hotel & 39 & 53 & 35 & 42 \\
\hline 5 & Daima Hotel & 39 & 55 & 34 & 43 \\
\hline 6 & Fave Hotel Olo & 40 & 55 & 40 & 45 \\
\hline 7 & Ibis Hotel & 74 & 69 & 72 & 72 \\
\hline 8 & Grand Inna Hotel & 58 & 73 & 65 & 65 \\
\hline 9 & Grand Zuri Hotel & 27 & 52 & 33 & 37 \\
\hline 10 & Kyriad Hotel Bumiminang & 44 & 42 & 39 & 42 \\
\hline
\end{tabular}

Sumber: Data penelitian, 2019

Nilai rata-rata tampilan visual feeds Instagram hotel-hotel berbintang di kota Padang tersebut dapat dilihat pada gambar berikut:

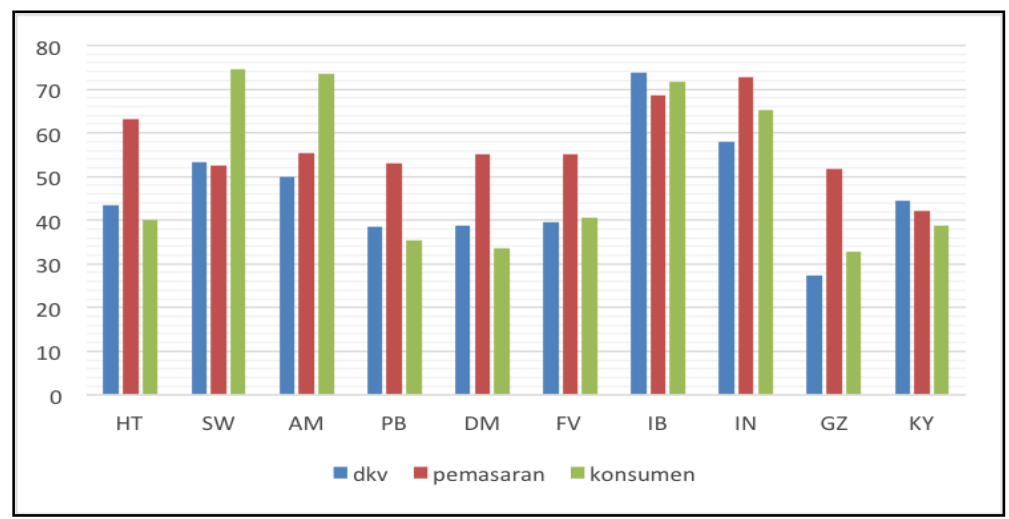

Gambar 1. Rata-rata Tampilan Visual Feeds Instagram Hotel-hotel Berbintang di Kota Padang

Sumber: olah data Microsoft excel ver. 2010, 2019 
Kemudian, untuk tampilan visual postingan Instagram hotel-hotel berbintang di kota Padang, didapatkan nilai rata-rata sebagai berikut:

Table 6 Nilai Rata-rata Tampilan Visual Postingan Instagram Hotel-hotel Berbintang di Kota Padang

\begin{tabular}{llllll}
\hline No & Hotel & $\begin{array}{l}\text { Ahli } \\
\text { DKV }\end{array}$ & $\begin{array}{l}\text { Ahli } \\
\text { Pemasaran }\end{array}$ & Konsumen & $\begin{array}{l}\text { Total } \\
\text { Rata-rata }\end{array}$ \\
\hline 1 & Hotel Hangtuah & 41 & 63 & 30 & 45 \\
\hline 2 & The Sriwijaya Hotel & 52 & 57 & 75 & 61 \\
\hline 3 & Amaris Hotel & 45 & 57 & 69 & 57 \\
\hline 4 & Plan B Hotel & 38 & 59 & 42 & 46 \\
\hline 5 & Daima Hotel & 43 & 49 & 22 & 38 \\
\hline 6 & Fave Hotel Olo & 43 & 61 & 75 & 60 \\
\hline 7 & Ibis Hotel & 66 & 68 & 59 & 64 \\
\hline 8 & Grand Inna Hotel & 51 & 71 & 77 & 66 \\
\hline 9 & Grand Zuri Hotel & 28 & 47 & 15 & 30 \\
\hline 10 & Kyriad Hotel Bumiminang & 49 & 49 & 55 & 51 \\
\hline
\end{tabular}

Sumber: data penelitian, 2019

Nilai rata-rata tampilan visual postingan Instagram hotel-hotel berbintang di kota Padang tersebut dapat dilihat pada gambar berikut:

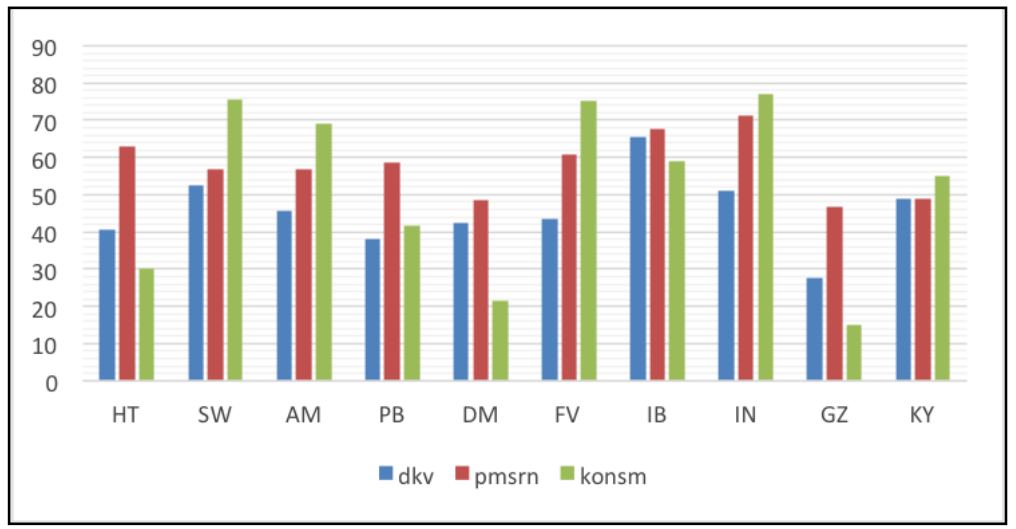

Gambar 2. Rata-rata Tampilan Visual Postingan Instagram Hotel-hotel Berbintang di Kota Padang

Sumber: olah data Microsoft excel ver. 2010, 2019

\section{Hotel Hangtuah Padang}

Tampilan visual feeds dan postingan Instagram Hotel Hangtuah Padang berada pada kategori cukup dengan nilai rata-rata 45 dan 49 , hal tersebut menunjukkan bahwa ahli DKV melihat bahwa media promosi online hotel ini belum memperhatikan aspek komunikasi visual. Hal yang sama juga disimpulkan oleh konsumen, bahwa hotel ini belum memperhatikan aspek komunikasi visual tersebut, sehingga konsumen merasa bahwa pesan yang ingin disampaikan belum mampu menarik perhatian konsumen. Namun, tidak demikian dengan ahli pemasaran, karena dari nilai yang diberikan, terlihat bahwa bagi ahli pemasaran tampilan visual feeds Instagram Hotel Hangtuah Padang sudah memenuhi tuntutan promosi. Berarti, bagi ahli pemasaran, yang dipentingkan adalah adanya media

cC (i) This is an open access article distributed under the Creative Commons 4.0 Attribution License, which permits unrestricted use, distribution, and reproduction in any medium, provided the original work is properly cited. (O2017 by author and Universitas Negeri Padang. 
promosi yang digunakan untuk sebuah produk, tanpa memikirkan aspek komunikasi visual, yang sebenarnya memiliki dampak lebih jauh terhadap pengambilan keputusan konsumen dalam membeli sebuah produk.

\section{The Sriwijaya Hotel Padang}

Tampilan visual feeds dan postingan Instagram The Sriwijaya Hotel Padang berada pada kategori cukup dan baik dengan nilai rata-rata 60 dan 61, hal tersebut menunjukkan bahwa ahli DKV melihat media promosi online hotel ini sudah cukup memperhatikan seni komunikasi visual walaupun tidak maksimal. Bagi konsumen, hotel ini sudah memperhatikan konten yang akan dimasukkan kedalam media promosinya dengan baik, sehingga konsumen pun berpendapat bahwa media promosi tersebut sudah mampu menarik perhatian konsumen, bahkan kontennya sesuai dengan apa yang dibutuhkan konsumen. Sementara, bagi ahli pemasaran, nampaknya mereka melihat dari sudut pandang kepentingan dan fungsi media promosi, yaitu tampilan visual feeds dan postingan Instagram hotel ini sudah memenuhi tuntutan customer value.

\section{Amaris Hotel Padang}

Tampilan visual feeds dan postingan Instagram Amaris Hotel Padang berada pada kategori cukup dengan nilai rata-rata 60 dan 57. Hal tersebut juga menunjukkan bahwa ahli DKV melihat media promosi online hotel ini sudah cukup memperhatikan seni komunikasi visualnya walaupun tidak maksimal. Ini menunjukkan bahwa hotel ini juga sudah memperhatikan aspek yang akan mendukung kelancaran bisnis perhotelan karena berkaitan dengan kegiatan pemasaran atau promosi yang dapat menentukan pencapaian keuntungan. Karena terlihat adanya perencanaan yang cukup baik dalam pembuatan Instagram mereka sebagai media promosi mengunggahnya di internet. bagi konsumen, Amaris Hotel Padang juga sudah memperhatikan konten yang akan dimasukkan ke dalam media promosinya dengan baik. bagi ahli pemasaran yang penilaiannya sama dengan ahli DKV, melihat pada kepentingan promosinya. Nilai cukup menunjukkan bahwa menurut ahli pemasaran, Amaris Hotel Padang sudah mempertimbangkan prinsip customer value.

\section{Plan B Hotel Padang}

Tampilan visual feeds dan postingan Instagram Plan B Hotel Padang berada pada kategori cukup dengan nilai rata-rata 42 dan 46, hal tersebut menunjukkan bahwa ahli DKV melihat media promosi online hotel ini kurang memperhatikan seni komunikasi visual. Tetapi, bagi ahli pemasaran dan konsumen, Plan B Hotel Padang sudah cukup memperhatikan konten yang akan dimasukkan ke dalam media promosinya, sehingga ahli pemasaran dan konsumen pun berpendapat bahwa media promosi tersebut sudah cukup mampu menarik perhatian konsumen. Hal ini berkemungkinan besar terjadi karena ahli DKV menitik-beratkan tampilan visual feeds dan postingan Instagram pada kepentingan komunikasi visual.

\section{Daima Hotel Padang}

Tampilan visual feeds dan postingan Instagram Plan B Hotel Padang berada pada kategori cukup dan kurang baik dengan nilai rata-rata 43 dan 38 . Hal tersebut menunjukkan bahwa ahli DKV melihat feeds Instagram masih kurang dan hal ini diperkuat oleh konsumen yang juga kurang menyukai feeds instagram Daima Hotel Padang. Akan tetapi, pada tampilan visual postingan Instagram, mereka berbeda pandangan. Ahli DKV menilai bahwa tampilan visual postingan Instagram hotel ini adalah cukup, tetapi bagi konsumen kurang baik. Perbedaan ini dimungkinkan karena perbedaan selera, bukan karena aspek komunikasi visual. Penilaian dari ahli DKV untuk tampilan visual feeds dan postingan 
Instagram yang secara berturut-turut berada pada kategori kurang baik dan cukup, sebenarnya menandakan bahwa media promosi online Daima Hotel Padang belum memperhatikan aspek komunikasi visual secara maksimal. Sementara, menurut ahli pemasaran, nilai tampilan visual feeds dan postingan Instagram Daima Hotel Padang samasama berada pada kategori cukup, karena ahli pemasaran nampaknya lebih menitikberatkan fungsi media sebagai alat promosi, dan tidak terlalu mempersoalkan aspek komunikasi visual.

\section{Fave Hotel Olo Padang}

Tampilan visual feeds dan postingan Instagram Fave Hotel Olo Padang berada pada kategori cukup dengan nilai rata-rata 45 dan 60 . Hal tersebut menunjukkan bahwa pada tampilan visual feeds Instagram Fave Hotel Olo Padang, ahli DKV dan konsumen melihat media promosi online hotel ini kurang memperhatikan aspek komunikasi visual. Hal ini menunjukkan bahwa tampilan visual feeds Instagram tersebut belum dapat mempermudah dan mempercepat informasi serta belum membantu menghasilkan makna dan menyentuh emosi yang membuat informasi lebih berkesan. konsumen juga merasa bahwa feeds Instagram Fave Hotel Olo Padang belum sesuai dengan kebutuhan mereka untuk membentuk estimasi kemampuan setiap produk dalam memenuhi kebutuhannya. pada tampilan visual postingan Instagram, ketiganya berbeda pandangan. Perbedaan antara ahli DKV dengan konsumen dimungkinkan karena perbedaan selera, bukan karena aspek komunikasi visual. Namun, perbedaan ahli DKVdengan ahli pemasaran lebih karena beda kepentingan. Menurut ahli pemasaran, fungsi media sebagai alat promosi lebih diutamakan dibandingkan dengan aspek komunikasi visual.

\section{Ibis Hotel Padang}

Tampilan visual feeds dan postingan Instagram Plan B Hotel Padang berada pada kategori baik dengan nilai rata-rata 72 dan 64 . Hal tersebut menunjukkan, pada tampilan visual feeds Instagram Ibis Hotel Padang, ahli DKV, ahli pemasaran dan konsumen melihat bahwa media promosi online hotel ini sudah memperhatikan aspek komunikasi visual sehingga pesan yang ada pada produk dapat ditangkap konsumen dengan baik. Akan tetapi, pada tampilan visual postingan Instagram, Ahli DKV dan Ahli Pemasaran berbeda pandangan dengan konsumen. Perbedaan ini dimungkinkan karena perbedaan selera, bukan karena aspek komunikasi visual, karena ahli DKV dan ahli pemasaran ternyata mempunyai penilaian yang sama.

\section{Grand Inna Hotel Padang}

Tampilan visual feeds dan postingan Instagram Grand Inna Hotel Padang berada pada kategori baik dengan nilai rata-rata 65 dan 66 . Hal tersebut menunjukkan, pada tampilan visual feeds dan postingan Instagram, ahli DKV melihat bahwa media promosi online hotel ini baru berkategori cukup. Namun, ahli pemasaran dan konsumen menilai bahwa tampilan visual feeds dan postingan Instagram Grand Inna Hotel Padang berada dalam kategori baik. Hal ini dapat dimengerti karena secara komunikasi visual, Instagram hotel ini sudah cukup mampu menyampaikan pesan produk kepada konsumen, sehingga wajar jika ahli pemasaran dan konsumen menilai tampilan visual feeds dan postingan Instagram Grand Inna Hotel Padang adalah baik. Lagipula, ahli DKV memberi kategori cukup, sehingga hal ini bisa dimaknai bahwa tampilan visual media promosi hotel ini sebagaimana dikatakan Kusrianto (2007) sudah cukup mampu menyampaikan pesan dan gagasan secara visual dengan

This is an open access article distributed under the Creative Commons 4.0 Attribution License, which permits unrestricted use, distribution, and reproduction in any medium, provided the original work is properly cited. $C 2017$ by author and Universitas Negeri Padang. 
mengelola elemen-elemen grafis, serta menurut ahli pemasaran, media promosi online hotel ini sudah memenuhi tuntutan customer value.

\section{Grand Zuri Hotel Padang}

Tampilan visual feeds dan postingan Instagram Grand Zuri Hotel Padang berada pada kategori kurang baik dengan nilai rata-rata 37 dan 30. Hal tersebut menunjukkan, ahli DKV dan konsumen melihat bahwa media promosi online Grand Zuri Hotel Padang adalah kurang bahkan tidak memperhatikan aspek komunikasi visual. bagi ahli pemasaran, Grand Zuri Hotel Padang ini sudah cukup memperhatikan konten yang akan dimasukkan ke dalam media promosinya, sehingga, bagi ahli pemasaran, media promosi tersebut sudah cukup mampu menarik perhatian konsumen. Padahal tidaklah demikian, karena ternyata konsumen justru memberi nilai tidak baik. Hal ini terjadi karena bagi ahli pemasaran yang dipentingkan adalah fungsi media promosinya saja, tanpa memperhatikan aspek customer value.

\section{Kyriad Hotel Bumiminang Padang}

Tampilan visual feeds dan postingan Instagram Kyriad Hotel Bumiminang Padang berada pada kategori cukup dengan nilai rata-rata 42 dan 51. Hal tersebut menunjukkan, ahli DKV dan ahli pemasaran melihat bahwa tampilan visual feeds dan postingan Instagram sebagai media promosi online Kyriad Hotel Bumiminang Padang sudah cukup memperhatikan aspek komunikasi visual walaupun tidak maksimal. Konsumen hotel ini juga menilai bahwa Kyriad Hotel Bumiminang Padang cukup memperhatikan konten yang akan dimasukkan ke dalam media promosinya, sehingga konsumen pun berpendapat bahwa media promosi tersebut cukup mampu menarik perhatian, walaupun pada tampilan visual feeds Instagram, konsumen memberi penilaian kurang baik, namun kontennya masih dirasa sesuai dengan apa yang dibutuhkan. bagi ahli pemasaran, walaupun penilaiannya sama dengan ahli DKV nampaknya mereka memiliki sudut pandang kepentingan yang berbeda. Ahli DKV melihat pada kepentingan desain komunikasi visual, sementara ahli pemasaran pada fungsi media promosi. Jadi sepanjang produk tersebut memiliki media promosi, bagi seorang ahli pemasaran, hal tersebut sudah dinilai baik.

\section{Rujukan}

Ayu, A.P. (2013). “Nirmana-Komposisi Tak Berbentuk” Sebagai Dasar Kesenirupaan. Fakultas Seni Rupa, Institut Kesenian Jakarta. Jurnal Ilmiah WIDYA Vol. 1, No. 2 Juli-Agustus 2013

Latifah, Arsianti (2009). Diktat Desain Komunikasi Visual I. Diktat Pendidikan Seni Rupa, Fakultas Bahasa dan Seni, Universitas Negeri Yogyakarta

Rizqia, Faradiba. (2017). 5 Cara Membuat Feed Instagram yang Rapi dan Menarik. https://kinibisa.com/artikel/detail/influencer (diakses pada tanggal 17/03/2019 pukul 10:35)

Sugiyono. (2015). Metode Penelitian Pendidikan Pendekatan Kuantitatif, Kualitatif dan R\&D. Bandung: Alfabeta. 